This paper is a summary of a session presented at the third annual German-American Frontiers of Science symposium, held June 20-22, 1997 at the Kardinal Wendel Haus in Munich, Germany.

\title{
Gene therapy
}

\author{
Mark A. Kay*†, Dexi Liu $\$$, and Peter M. Hoogerbrugge§ \\ *Division of Medical Genetics, Department of Medicine, University of Washington, Seattle, WA 98195; $\ddagger$ Department of Pharmaceutical Sciences, University of \\ Pittsburgh, Pittsburgh, PA 15261; and §Department of Pediatrics, University of Leiden, Leiden, The Netherlands
}

\begin{abstract}
In recent years, there have been a number of technological breakthroughs that have allowed for clinical trials in gene therapy to be initiated. In combination with the genome initiative, the potential for new therapeutics is limitless. Although an enormous amount of information has been obtained in a relatively short period of time, gene therapy is not yet ready for wide-scale practice. Some of the successes and obstacles that remain are summarized in this report.
\end{abstract}

\section{Gene Therapy: The Problem}

Gene therapy can be defined as the introduction of nucleic acids into cells for the purpose of altering the course of a medical condition or disease. In general, with some exceptions, the nucleic acids are DNA molecules encoding gene products or proteins. The original ideas were directed toward treating monogenic (single-gene) disorders, but it has become clear that the gene can be considered a new pharmaceutical agent for treating many types of diseases. Over the last 20 years, the initial thoughts of gene therapy have been transformed into reality with more than 175 clinical trials and 2,000 patients already treated (1). Yet with all the trials, there is still no conclusive evidence for efficacy. Although the expectations have exceeded the initial success of this relatively new field, important information has been gained from preclinical and clinical trials. With this in mind, it is imperative to realize that with recent technological advances, gene therapy for treating a wide variety of diseases is likely to become a reality within the early part of the next century.

There are clearly a number of obstacles limiting successful gene therapy, but the most difficult to overcome has been the inability to transfer the appropriate gene into a target, non-germ-cell tissue, such that an appropriate amount of gene product (usually a protein) is produced to correct the disease. The cell/organism has developed powerful mechanisms to avoid the accumulation of extraneous genetic material. The purpose of this session was to illustrate both the highlights as well as hurdles that remain for developing successful clinical applications.

\section{Vehicles for Gene Transfer}

There are two major classes of vehicles for gene transfer: viral and nonviral vectors. This report will concentrate on vectors that have been used in clinical trials (see Table 1). Some researchers believe that viruses will be most successful because they have evolved for millions of years to become efficient vesicles for transferring genetic material into cells, whereas others believe that some of the side-effects of viruses and possible previous exposures rendering the host resistant to transduction (gene transfer into the cell) will preclude their long-term use in gene therapy. Once a vector is designed, two general approaches are used for gene transfer: $e x$ vivo where cells are removed, genetically modified, and transplanted back into the same recipient, and in vivo therapy accomplished by transfer of genetic materials directly into the patient.

(C) 1997 by The National Academy of Sciences 0027-8424/97/9412744-3\$2.00/0 PNAS is available online at http://www.pnas.org.
The latter is preferable in most situations, because the complexity of the former method makes it less feasible for wide-scale application.

\section{Viral Vectors for Gene Therapy}

Three different classes of viral vectors have been used in clinical trials. The first relates to recombinant retroviruses. To date, retroviruses based on the Mouse Moloney Leukemia virus have been used most frequently in clinical trials. These vectors are packaged into viral particles, have all viral genes removed but contain some of the viral regulatory sequences, and will only transduce dividing cells. Although efficient at transduction into cells in culture, most cells in vivo are quiescent at any point in time, making this vector less useful for in vivo therapies unless the cells in a target organ are stimulated to cycle. A second disadvantage of retroviruses is the relatively low concentration of virus that can be easily produced. More recently, a chimeric Moloney-Human lentiviral (HIV) vector has been constructed that can transduce at least some quiescent cells in vivo including neurons in the brain of rodents (2). This promising advance will require further studies to determine the vector's application in the clinic.

In general, human adenoviruses are responsible for mild illnesses such as upper respiratory infections. The more common serotypes ( 2 and 5 ) have been exploited for use in clinical trials for cystic fibrosis and cancer. This 36-kb double-stranded DNA virus contains genes that express more than 50 gene products throughout its life cycle. By eliminating the E1 region of the vector, two goals are accomplished: space is made for placing therapeutic expression sequences and, in the absence of the transactivating E1a protein, the virus cannot replicate. Thus, after gene transfer, no viral spread will occur. These first-generation adenoviral vectors were demonstrated to be very efficient at transferring genes into most tissues after in vivo administration. In contrast to retroviruses, these vectors can be concentrated to high titer (10e12/ml), can transduce nondividing cells, and do not integrate into host chromosomal DNA. As a result, these vectors were used to temporarily cure a number of animal models with specific genetic diseases like hemophilia (3) and hypercholesterolenemia $(4,5)$. Enthusiasm for these vectors was tempered by the discovery that low-level production of viral antigens from the vector elicited a robust immunologic response that eliminated transduced cells and transgene product and/or inhibited repeat administration. These studies have prompted a plethora of studies related to vector-host interactions with the hope that the immunologic barriers could be overcome. Several approaches currently are being pursued. One includes deleting the viral genes that are the most immunogenic, and, more recently, clever methods have been devised to remove all or most of the viral genes (6-8).

The Frontiers of Science symposia is the latest in the series "From the Academy," which is presented occasionally to highlight work of the Academy, including the science underlying reports of the National Research Council.

†To whom correspondence should be addressed. e-mail: mkay@u. washington.edu. 
Table 1. Gene transfer vehicles

\begin{tabular}{lll}
\hline \multicolumn{1}{c}{ Vector } & \multicolumn{1}{c}{ Advantages } & \multicolumn{1}{c}{ Disadvantages } \\
\hline Viral & & \\
Retrovirus & Integration into host DNA & Semi-random integration \\
& All viral genes removed & Transduction requires cell division \\
& Relatively safe & Relatively low titer \\
Tdenovicity & Immunological response \\
& Higher titer & Efficient transduction of \\
nondividing cells in vitro and in vivo & Prior exposure \\
Adeno-associated virus & All viral genes removed & Small genome limits size of foreign DNA \\
& Safe & Labor-intensive production \\
& Transduction of nondividing cells & Status of genome not fully elucidated \\
Nonviral & Stable expression & \\
Liposomes & Absence of viral components & \\
& Lack of previous immune recognition & Inefficient gene transfer into the nucleus \\
& & Lack of persistence of DNA \\
& Lack of tissue targeting \\
\hline
\end{tabular}

Because of the complexity of the viral genome and toxicity associated with production of some of the viral proteins at sufficient levels to make the virus, removal of these genes has been more difficult than for retroviruses. How well these futuregeneration adenoviral vectors will function in vivo is currently being determined. Even if the genes are removed, there will be some level of immunity related to transgene production and the vector capsid itself. Thus, newer immunomodulatory agents that are more selective and are only administered for a brief period may be useful in blocking these immune responses, as demonstrated in several animal models (9).

Recombinant adeno-associated virus (AAV) vectors contain small, single-stranded DNA genomes and have recently been shown to transduce brain $(10)$, skeletal muscle $(11,12)$, and liver (13) by injection into quiescent tissue or vasculature, feeding the tissue in animals. In fact, rAAV has been used to achieve therapeutic (14) or, in some cases, curative (13) concentrations of clotting factor IX in mice without toxicity for at least 9 months by in vivo delivery. Unfortunately, these vectors have a disadvantage in that there is a limit in the amount of DNA that can be packaged. Thus, larger cDNAs, genes, or complex regulatory cis elements cannot be used with this vector.

Regulation of gene expression may be important for treating some diseases, and recently, several different approaches to regulate gene expression have been used in animal models of gene expression. These approaches include the addition or subtraction of small molecules that interact with cis DNA elements and turn genes on or off. Moreover, tissue-specific regulation can be achieved by using cell-type-specific promoters or by designing vectors that specifically target an organ. Altering the tropism of the vector by constructing new ligands for receptor-specific targeting will certainly be important for future gene therapy applications.

There are a number of additional viral vectors based on Epstein-Barr virus, herpes, simian virus 40, papilloma, nonhuman lentiviruses, and hepatitis viruses that are currently being derived in the laboratory. Perhaps these chimeric or as yet undiscovered viruses will have properties that offer advantages to clinical gene therapy that are not yet realized.

\section{Nonviral Vectors: Liposomes}

Compared with viral vectors, cationic lipid-based delivery systems have several advantages. Unlike viral vectors, DNA/ lipid complexes are easy to prepare and there is no limit to the size of genes that can be delivered. Because carrier systems lack proteins, they may evoke much less immunogenic responses. More importantly, the cationic lipid systems have much less risk of generating the infectious form or inducing tumorigenic mutations because genes delivered have low integration frequency and cannot replicate or recombine.
During the last few years, two classes of cationic lipids have been synthesized and show good transfection activity, which is mostly in vitro with established cell lines $(15,16)$. The first class has two alkyl chains in each cationic lipid molecule, and the other type uses cholesterol as the backbone. Both types of lipid contain either mono- or multiple-amino groups as the cationic function group to form complexes with DNA via electrostatic interactions. Each type of cationic lipid appears to have its preferred cell lines for an optimal transfection activity, even though both types of cationic lipids may show similar levels of transfection activity in a given cell type. With a few exceptions, the transfection activity of these cationic lipids is improved when a helper lipid, dioleoylphosphatidlylethanolamine, is included as part of the liposome composition (17-19). In general, the transfection activity of these cationic liposomes in vitro is optimal with slight excess of cationic lipid in the DNA/lipid complexes (17-19).

Despite the early success of cationic lipid systems in transfecting cells mostly in vitro or in vivo by a local regional administration (20), no solid evidence has been presented in support of their gene transfer efficiency in vivo through systemic administration. This is largely due to some technical difficulty in preparing DNA/lipid complexes at concentrations where the injection volume into the animals is not too large and large aggregates will not form. However, such technical problems have been solved to a certain degree. A few recent reports have demonstrated that it is now possible to make a homogeneous solution with a higher concentration of DNA/lipid complexes by using either a much higher cationic-to-DNA ratio (21) than that used in in vitro transfection or by including into the lipids nonionic surfactants such as Tween $80(22,23)$ or other polyethylene-based amphiphiles (24). Using rodents, it has been shown that nanogram levels of gene product per milligram of proteins from the tissue extract can be achieved by a single tail vein injection of $25 \mu \mathrm{g}$ of plasmid DNA containing the luciferase gene as a reporter $(21,25)$. Among the organs including lung, liver, spleen, heart, and kidney, the level of gene expression is the highest in the lung. Confocal microscopic study of the transfected lung using green fluorescence protein gene as the reporter indicates that the lung endothelial cells are the type of cells transfected (21). Time course shows that gene expression in different organs is transient, with the peak level between 8 and $20 \mathrm{hr}$ and drops to less than $1 \%$ of the peak level by day 4 . Results from Southern analysis suggest that such transient gene expression is likely due to the degradation of the transgene (21). However, the same level of gene expression can be regained by repeated injection after an interval of 2-3 weeks (21).

Although additional experiments are needed to show that gene expression in vivo by an intravenous administration will be useful for therapeutic purposes, these in vivo results reconfirm the potential of the lipid system as a carrier for gene therapy. As with 
viral vectors, the next challenges are to achieve targeted gene delivery, to control the level of transgene expression, and to devise methods for long-term expression when needed.

\section{Gene Therapy for Hematopoietic Derived Diseases}

So far, most clinical trials on gene therapy focus on gene transfer into hematopoietic (blood cells) and cancer cells. In this report, we will illustrate the development of studies on gene transfer into hematopoietic stem cells. All hematopoietic cells arise from a single cell type designated as pluripotent hematopoietic stem cells (PHSCs). Therefore, successful stem cell gene therapy can be applied to a large variety of congenital and acquired blood cell diseases. In the last few years, the cell fraction that includes these PHSCs is being identified using molecules that are present on the cell surface; e.g., it has been found that PHSCs carry the CD34 antigen (CD34+; this is present in approximately $1 \%$ of the bone marrow cells) but are negative for other markers ("lin" neg, which is the case in approximately $1 \%$ of the CD34+ cells). By cell separation techniques, the CD34+ lin ${ }^{\text {neg }}$ cells can be isolated and used for gene transfer studies. In these stem cell gene transfer studies, the cells are harvested from the patient, gene transfer is performed ex vivo, and the transduced cells are subsequently reinfused into the patients. The majority of studies use retroviral vectors as vehicles to mediate gene transfer. Initial trials aiming at gene transfer into hematopoietic cells focused on transfer of the gene encoding adenosine deaminase (ADA) (26-29). Deficiency of ADA results in a T cell defect, leading to a disease called severe combined immune deficiency. Patients with this genetic disease generally die in the first years of life due to overwhelming infections. At the moment these initial gene transfer trials started, gene transfer frequency into stem cells of larger animals such as dogs and monkeys was less than 3\% (30-31). Despite this low frequency, clinical trials were initiated, because it was known from bone marrow transplantation experiments that "healthy cells" had a growth advantage over "diseased cells." Therefore, it was hoped that infusion of a low number of genetically repaired cells would result in the outgrowth of a functional immune system. So far, however, the frequency of transduced cells in blood is lower than the $3 \%$ reported in larger animal studies. A possible explanation may be that the "human hematopoietic stem cell" is more resistant to transduction than the animal's stem cells. It has also been suggested that, because the lack of pretreatment or conditioning used in animals may affect the outcome of the clinical studies, the transduced cells are only $0.001 \%$ of the endogenous stem cells of the patient, which is too low to result in detectable, stable engraftment. However, in similar experiments using animal models, the number of endogenous stem cells was reduced to virtually none by myeloablative therapy. Due to this myeloablation, the proportion of transduced cells following infusion was much higher and resulted in the long-lasting presence of transduced cells (32). Higher-efficiency gene transfer into human hematopoietic stem cells may occur during very long $e x$ vivo cultivation of the stem cells over a bone marrow stroma cell layer.

Besides clinical studies in ADA-deficient patients, gene transfer into hematopoietic stem cells has been studied in so-called gene-marking studies (33). These studies are performed in patients who are treated for a malignancy with high-dose cytotoxic therapy, followed by reinfusion of their own stem cells that are harvested earlier in the course of the disease. In these patients, the majority of the graft is reinfused unmodified as a stem cell rescue, but a part of the graft is used for gene-transfer studies with marker genes. Also in these patients, the percentage of genetically marked blood cells after gene transfer is $<1 \%$. At present, it is generally believed that our limited knowledge in basic stem cell biology is the major bottleneck of stem cell gene transfer studies. For example, questions to be addressed include whether or not receptors for viral vectors are expressed and whether it is possible to trigger stem cells into cycle ex vivo without loss of pluripotency.

This work was supported by National Institutes of Health Grant HL53682 (M.A.K.).

1. Ross, G., Erickson R., Knorr, R., Motulsky, A. G., Parkman, R., Samulski, J., Straus, S. E. \& Smith, B. R. (1996) Hum. Gene Ther. 7, 1781-1790.

2. Naldini, L., Blomer, U., Gage, F. H., Trono, D. \& Verma, I. (1996) Proc. Natl. Acad. Sci. USA 93, 11382-11389.

3. Kay, M. A., Landen, C. N., Rothenberg, S. R., Taylor, L. A., Leland, F. Wiehle, S. Fang, B., Bellinger, D., Finegold, M., Thompson, A. R., Read, M., Brinkhous, K. M. \& Woo, S. L. C. (1994) Proc. Natl. Acad. Sci. USA 91, 2353-2357.

4. Ishibashi, S., Brown, M. S., Goldstein, J. L., Gerard, R. D., Hammer, R. E. \& Herz, J. (1993) J. Clin. Invest. 92, 883-893.

5. Kozarsky, K. F., McKinley, D. R., Austin, L. L., Raper, S. E., StratfordPerricaudet, L. D. \& Wilson, J. M. (1994) J. Biol. Chem. 269, 13695-13702

6. Mitani, K., Graham, F. L., Caskey, C. T. \& Kochanek, S. (1995) Proc. Natl. Acad. Sci. USA 92, 3854-3858.

7. Lieber, A., He, C. Y., Kirillova, I. \& Kay, M. A. (1996) J. Virol. 70, 8944-8959.

8. Parks, R. J., Chen, L., Anton, M., Sankar, U., Rudnicki, M. A. \& Graham, F. L. (1996) Proc. Natl. Acad. Sci. USA 93, 13565-13570.

9. Kay, M. A., Meuse, L., Gown, A. M., Linsley, P., Hollenbaugh, D., Aruffo, A., Ochs, H. D. \& Wilson, C. B. (1997) Proc. Natl. Acad. Sci. USA 94, 4686-4691.

10. McCowan, T. J., Xiao, X., Bresse, G. R. \& Samulski, R. J. (1996) Brain Res 713, 99-107.

11. Fisher, K. J., Jooss, K., Alston, J., Yang, Y., Haecker, S. E., High, K. Pathak, R., Raper, S. E. \& Wilson, J. M. (1997) Nat. Med. 3, 306-312.

12. Xiao, X., Li, J. \& Samulski, R. J. (1996) J. Virol. 70, 8098-8108.

13. Snyder, R. O., Miao, C. H., Patijn, G. A., Spratt, S. K., Danos, O., Nagy, D., Gown, A. M., Winther, B., Meuse, L., Cohen, L. K., Thompson, A. R. \& Kay, M. A. (1997) Nat. Genet. 16, 270-276.

14. Herzog, R. W., Hagstrom, J. N., Kung, S. H., Tai, S. J., Wilson, J. M., Fisher, K. J. \& High, K. (1997) Proc. Natl. Acad. Sci. USA 94, 5804-5809.

15. Gao, X. \& Huang L. (1995) Gene Ther. 2, 710-722.

16. Behr, J. P. (1994) Bioconjugate Chem. 5, 382-389.

17. Felgner, P. L., Gadek, T. R., Holm, M., Roman, R., Chan, H. S., Wenz, M., Northerop, J. P., Ringold, M. \& Danielsen, H. (1987) Proc. Natl. Acad. Sci. USA 84, 7413-7417.

18. Gao, X. \& Huang, L. (1991) Biochem. Biophys. Res. Commun. 179, 280-285.

19. Felgner, J. L., Kumar, R., Sridhar, C. N., Wheeler, C. J., Tsai, Y. J., Border, R., Ramsey, P., Martin, M. \& Felgner, P. L. (1994) J. Biol. Chem. 269, $2550-2561$.

20. Nabel, G. J., Nabel, E. G., Yang, Z. Y., Fox, B. A., Plautz, G. E., Gao, X., Huang, L., Shu, S., Gordon, D. \& Chang, A. E. (1993) Proc. Natl. Acad. Sci. USA 90, 11307-11311.

21. Song, Y. K., Chu, S. Y. \& Liu, D. (1997) Hum. Gene Ther, in press.

22. Liu, F., Yang, J. P., Huang, L. \& Liu, D. (1996) Pharm. Res. 13, 1856-1860.

23. Liu, F., Yang, J. P., Huang, L. \& Liu, D. (1996) Pharm. Res. 13, 1642-1646.

24. Hong, K., Zheng, W., Baker, A. \& Papahadjopoulos, D. (1997) FEBS Lett. 400, $233-237$.

25. Liu, F., Qi, H., Huang, L. \& Liu, D. (1997) Gene Ther. 4, 517-523.

26. Blaese R. M., Culver, K. W., Miller, A. D., Carter, C. S., Fleisher, T., Clerici, M., Shearer, G., Chang, L., Chiang, Y., Tolstoshev, P., Greenblatt, J. J., Rosenberg, S. A., Klein, H., Berger, M., Mullen, C. A., Ramsey, W. J., Muul, L., Morgan, R. A. \& Anderson, W. F. (1995) Science 270, 475-480.

27. Hoogerbrugge, P. M., van-Beusechem, V. W., Fischer, A., De-bree, M. le-Deist, F., Perignon, J. L., Morgan, G., Gaspar, B., Faribanks, L. D., Skeoch, C. H., Moseley, A., Harvey, M., Levinsky, R. J. \& Valerio, D. (1996) Gene Ther. 3, 179-183.

28. Kohn, D. B., Weinberg, K. I., Nolta, J. A., Heiss, L. N., Lenarsky, C., et al. (1995) Nat. Med. 1, 1017-1023.

29. Bordignon, C., Notarangelo, L. D., Nobili, N., Ferrari, G., Casorati, G., Panina, P., Mazzolari, E., Maggioni, D., Rossi, C., Servida, P., Ugazio, A. G. \& Mavilio, F. (1995) Science 270, 470-475.

30. Bodine, D. M., Moritz, T., Donahue, R. E., Luskey, B. D., Kessler, S. W., Martin, D. I., Orkin, S., Neinhus, A. W. \& Williams, D. A. (1993) Blood 82 1975-1980.

31. Beusechem, V. W., Kukler, A., Heidt, P. J. \& Valerio, D. (1992) Proc. Natl. Acad. Sci. USA 89, 7640-7644.

32. Bienzle, D., Abrams-Ogg, A. C., Kruth, S. A., Ackland-Snow, J., Carter, R. F., Dick, J. E., Jacobs, R. M., Kamel-Reid, S. \& Dube, I. D. (1994) Proc. Natl. Acad. Sci. USA 91, 350-354.

33. Brenner, M. K., Rill, D. R., Moen, R. C., Krance, R. A., Mirro, J., Jr., Anderson, W. F. \& Ihle, J. N. (1993) Lancet i, 85-86. 